\title{
REVIEW \\ Peripheral vascular function in spinal cord injury: a systematic review
}

\author{
CR West ${ }^{1}$, A AlYahya ${ }^{2}$, I Laher ${ }^{3}$ and A Krassioukov ${ }^{1,4,5}$
}

Background: During the past 20 years, significant advances in patient care have resulted in individuals with spinal cord injury (SCI) living longer than before. As lifespan increases, cardiovascular complications are emerging as the leading cause of mortality in this population, and individuals with $\mathrm{SCl}$ develop cardiovascular disease at younger ages than their able-bodied counterparts. To address this increasing clinical challenge, several recent studies investigated the central cardiovascular adaptations that occur following SCl. However, a somewhat less recognized component of cardiovascular dysfunction in this population is the peripheral vascular adaptations that also occur as a result of SCl.

Study design: Literature review.

Objective: To present a comprehensive overview of changes in arterial structure and function, which occur after $\mathrm{SCl}$.

Setting: Canada.

Methods: A systematic literature review was conducted to extract studies that incorporated measures of arterial structure or function after $\mathrm{SCl}$ in animals or humans.

Results: Individuals with $\mathrm{SCl}$ exhibit vascular dysfunction below the lesion that is characterized by a reduction in conduit artery diameter and blood flow, increased shear rate and leg vascular resistance, and adrenoceptor hyper-responsiveness. There is also recent alarming evidence for central arterial stiffening in individuals with SCl.

Conclusion: Although physical deconditioning is the primary candidate responsible for the maladaptive remodeling of the peripheral vasculature after $\mathrm{SCl}$, there is emerging evidence that blood pressure oscillations, such as those occurring in the large majority of individuals with $\mathrm{SCl}$, also exacerbates vascular dysfunction in this population.

Spinal Cord (2013) 51, 10-19; doi:10.1038/sc.2012.136; published online 27 November 2012

Keywords: cardiovascular; autonomic; tetraplegia; paraplegia; arterial

\section{INTRODUCTION}

A spinal cord injury (SCI) is among the most devastating and debilitating conditions an individual can sustain. The most recent estimates of SCI incidence in the United States vary from 25 to 59 new cases per million inhabitants per year, with an average of 40 per million. ${ }^{1}$ In addition to severe motor and sensory dysfunction, SCI also disrupts autonomic pathways ${ }^{2}$ and consequently perturbs cardiovascular homeostasis. Cardiovascular complications in the early stages of high SCI can be life-threatening, and include profound hypotension, bradyarrhythmias and cardiac arrest. ${ }^{3}$ There is also alarming recent evidence demonstrating an increased risk of ischemic stroke after SCI. ${ }^{4}$ Although some of these complications can improve in the weeks following SCI, cardiovascular control rarely returns to pre-injury baseline.

Individuals with SCI are at increased risk for cardiovascular disease (CVD) compared with their able-bodied (AB) counterparts; ${ }^{5}$ however, the factors that contribute to the elevated risk in this population are not well understood. CVD risk prediction is typically based on factors such as sex, age, diabetes, blood lipid profile, elevated systolic blood pressure and smoking status. ${ }^{6}$ These 'traditional' risk factors, however, do not fully explain the increased CVD risk in individuals with SCI. ${ }^{7}$ For instance, people with high-thoracic/cervical SCI exhibit autonomic disturbances that result in a low resting arterial blood pressure ${ }^{8}$ - something that is usually considered cardioprotective-yet they exhibit a greater prevalence of CVD than the $\mathrm{AB}$ population. Thus, other factors must at least partly be responsible for the elevated CVD risk in the SCI population, and recent evidence suggests that there is a need for more specific recommendations for the management of CVD in the SCI population. ${ }^{9}$ In the $\mathrm{AB}$ population, studies that have investigated the reduction in CVD risk with exercise have reported that only 40 $60 \%$ of the risk reduction is explained by improvements in traditional CVD risk factors. ${ }^{10}$ It has been postulated that exercise-induced improvements in endothelial function may be responsible for this 'risk factor gap.' ${ }^{11,12}$ To our knowledge, dysfunction of the peripheral vasculature as a contributor to CVD in the SCI population has not been investigated. Indeed, most studies describing cardiovascular changes after SCI have focused on central cardiovascular adaptations. ${ }^{13-15}$ This is somewhat surprising: as we will describe in this review, SCI induces vascular deconditioning below the level of

${ }^{1}$ International Collaboration on Repair Discoveries (ICORD)-BSCC, UBC, Vancouver, British Columbia, Canada; ${ }^{2}$ Pharmacology Department, College of Pharmacy, King Saud University, Riyadh, Saudi Arabia; ${ }^{3}$ Department of Pharmacology, University of British Columbia, Vancouver, British Columbia, Canada; ${ }^{4}$ Department of Medicine, University of British Columbia, Vancouver, British Columbia, Canada and ${ }^{5}$ GF Strong Rehabilitation Centre, Vancouver, British Columbia, Canada

Correspondence: Dr A Krassioukov, International Collaboration on Repair Discoveries (ICORD)-BSCC, UBC, 818 West 10 th Avenue, Vancouver, V5Z 1 M9 British Columbia, Canada.

E-mail: krassioukov@icord.org.

Received 18 July 2012; revised 1 October 2012; accepted 8 October 2012; published online 27 November 2012 
injury and disrupts supraspinal control of the spinal sympathetic circuits that ultimately innervate the adventitial-media layer of blood vessels, both of which lead to a multitude of vascular abnormalities that may contribute to elevated CVD risk. ${ }^{16}$ It is highly likely, therefore, that adaptations in the peripheral vasculature after SCI are of equal, if not greater, clinical importance than the wellrecognized central cardiovascular adaptations that occur in this population. Accordingly, the aim of this review is threefold: (1) to provide an overview of the autonomic nervous system and blood vessel structure and function; (2) to describe changes thereof following SCI; and (3) to discuss the effects that loss of sympathetic neural control and physical deconditioning has on the peripheral vasculature in the SCI population.

\section{METHODS}

A systematic review of the literature to extract studies that incorporated measures of arterial structure or function after SCI in animals or humans was conducted using the following online databases: MEDLINE, EMBASE and SPORTDiscus. Population search terms included: spinal cord injury, paraplegia, tetraplegia and quadriplegia. Vascular keywords included: arterial, vasculature, peripheral, cardiovascular, sympathetic, parasympathetic, vascular stiffness, vascular compliance, adrenoceptor, hyper-responsiveness, shear stress, shear rate, hypertension, blood pressure, autonomic dysreflexia (AD), endothelial, leg blood flow, femoral and carotid. Exercise keywords included: functional electrical stimulation (FES), cycling, treadmill, wheelchair, body-weight-supported treadmill training, passive and resistance. Abstracts were reviewed to identify relevant studies, and where the relevant information was not available in the abstract, the Methods section was also reviewed. All studies published in English that incorporated measures of arterial structure or function at rest or in response to an intervention in humans or animals with SCI were included. A total of 36 studies were included in the review. For the purpose of this review, we use the term 'peripheral' to denote blood vessels outside of the central nervous system (brain and spinal cord).

\section{ORGANIZATION OF THE AUTONOMIC NERVOUS SYSTEM}

The autonomic nervous system is divided into two primary components: sympathetic and parasympathetic. The sympathetic nervous system (SNS) is considered 'excitatory', whereas the parasympathetic nervous system (PNS) is 'suppressive'; collectively, these systems provide balanced autonomic control. Both divisions of the autonomic nervous system innervate the majority of visceral organs, including the heart. ${ }^{2}$ Exceptions to this rule are the majority of blood vessels, which receive only sympathetic innervations, and the cavernous tissue of the penis and clitoris, which receive only parasympathetic innervations. However, there is also evidence that the cerebral and pulmonary blood vessels also have parasympathetic innervations. ${ }^{17}$ Finally, peptidergic, purinergic and nitrigic sensory fibers also innervate all blood vessels and cavernous tissues. Despite functional differences, the organization of the SNS and parasympathetic nervous system share some similarities. For example, both divisions of the autonomic nervous system have two neuronal populations. The first neuronal population is the preganglionic neurons, whose cell body is in the gray matter of the brain or spinal cord. Sympathetic and parasympathetic preganglionic neurons are cholinergic and release the neurotransmitter acetylcholine. Preganglionic nerves travel in the anterior roots of the spinal cord or cranial nerves and synapse on the second population of neurons, the postganglionic neurons, which are located in the autonomic ganglia of the peripheral nervous system. ${ }^{18}$ The axons of the postganglionic neurons then synapse with the target organs.

Preganglionic neurons of the SNS originate in the spinal gray matter in the thoracic (T1-T12) and upper lumbar segments of the spine (L1-L2). Axons of the sympathetic preganglionic neurons exit through the anterior roots of the spinal cord and synapse onto postganglionic sympathetic neurons in the sympathetic chain ganglia and prevertebral ganglia. Sympathetic postganglionic fibers are longer than those of the cholinergic nervous system and are mostly adrenergic, releasing the neurotransmitter norepinephrine (NE); an exception is the sympathetic fibers innervating sweat glands and piloerector muscles, which release acetylcholine. The segmental sympathetic innervations that are particularly important for understanding cardiovascular control in individuals with SCI are the sympathetic innervation of the heart at T1-T4, the blood vessels of the upper limbs at T1-T4 and the blood vessels of the splanchnic bed and lower limbs at T6-L2 (Figure 1).

Preganglionic neurons of the parasympathetic nervous system originate within four cranial nerves (CN III, VII, IX and X) of the brainstem and within the sacral spinal segments (S2-S4). ${ }^{2,19}$ In contrast to the SNS, there is no parasympathetic innervation of the peripheral vasculature. The heart and pulmonary tree, however, are under parasympathetic control through the vagus nerve $(\mathrm{CN} \mathrm{X})$, a cranial nerve that exits the brainstem and synapses with the sinoatrial node and the nerve cells in the enteric nervous system; hence, the upper portion of the gastrointestinal tract also receives parasympathetic innervation. ${ }^{19}$

\section{CARDIOVASCULAR CONTROL AFTER SCI}

Following SCI there is loss or decrease of the central sympathetic tone (neurogenic-originates from supraspinal neuronal centers). Although peripheral tone (myogenic - originates from smooth muscle of the blood vessels) is preserved, it is inadequate at maintaining arterial blood pressure following high thoracic or cervical SCI. Consequently, the acute period after SCI is characterized by profound hypotension, and pharmacological intervention via vasopressive therapy may be required to maintain arterial blood pressure during this period. ${ }^{20,21}$ Of particular importance in the development of hypotension is the loss of sympathetic tonic activity to a significant portion of the peripheral blood vessels below the lesion; hence, those with the highest (cervical) injuries exhibit the most severe hypotension. ${ }^{8}$ In addition to resting hypotension, most individuals with high SCI experience orthostatic hypotension when transferring from a supine to a seated position. ${ }^{22-26}$ In the $A B$ population, it is well known that on assumption of the upright posture, there is a baroreflex-mediated peripheral vasoconstriction via an increased sympathetic outflow to maintain blood pressure and cerebral perfusion..$^{27,28}$ It is, therefore, likely that both sympathetic hypoactivity and altered baroreceptor sensitivity are the primary causes of orthostatic hypotension following cervical SCI. ${ }^{29,30}$ However, a lack of skeletal muscle pump, ${ }^{31}$ cardiovascular deconditioning ${ }^{32}$ and/or altered salt and water balance ${ }^{33}$ have also been hypothesized to contribute to hypotension.

Initially, in the acute period of SCI both individuals with tetraplegia and paraplegia present with significant orthostatic hypotension. ${ }^{34}$ With time post injury, however, it has been demonstrated that individuals with thoracic SCI exhibit an increase in leg vascular resistance during head-up tilt that is consistent with that in the $A B$ population. ${ }^{35-37}$ The increase in leg vascular resistance was attributed to a local myogenic response triggered by changes in vascular pressure changes during head-up tilt. ${ }^{35}$ It should be noted, however, that those 


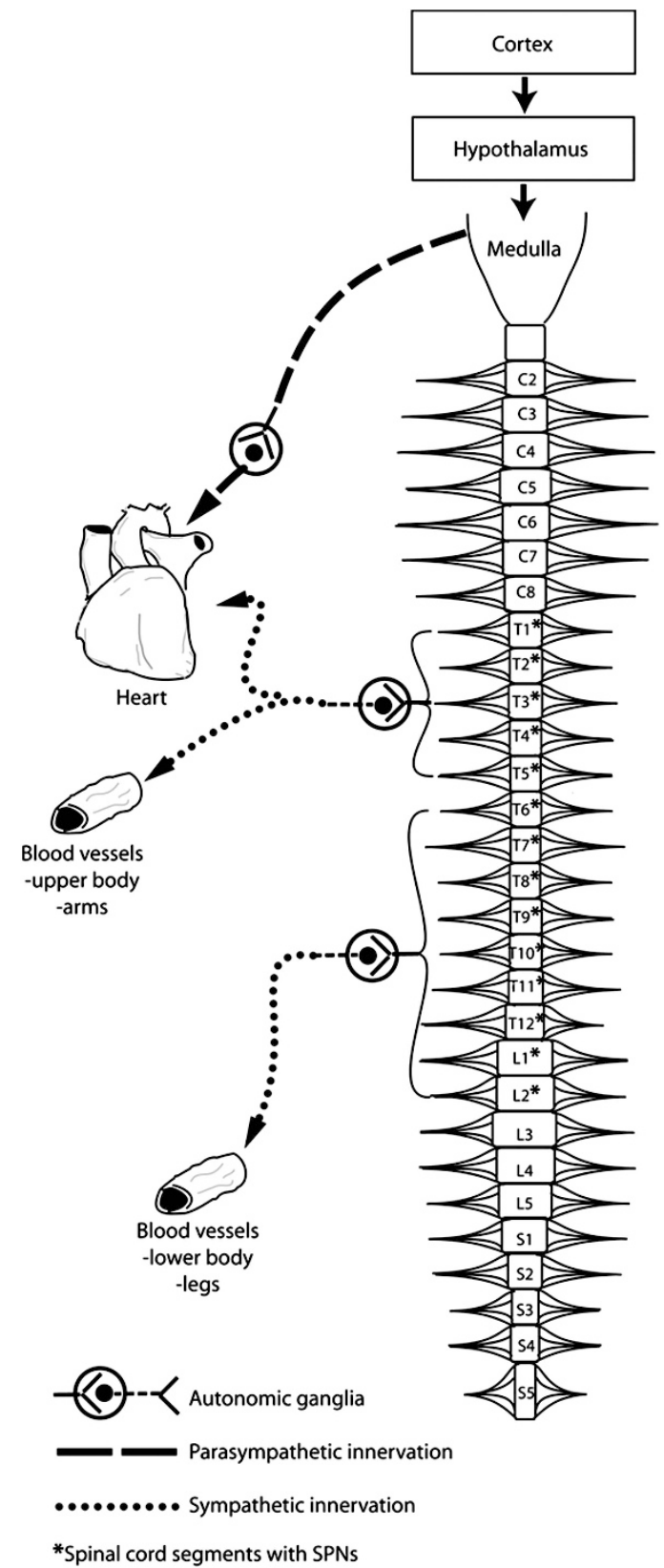

Figure 1 Autonomic control of the cardiovascular system. Parasympathetic pre-ganglionic fibers exit the brainstem via the vagus nerve and synapse with post-ganglionic parasympathetic neurons in the cardiac ganglia. The majority of sympathetic pre-ganglionic neurons are located within the lateral horn of spinal segments T1-L2. Axons of these neurons exit the spinal cord via the ventral root and synapse with post-ganglionic neurons located in the paravertebral ganglia. The post-ganglionic fibers then synapse directly with smooth muscle in the heart and blood vessels. Figure adapted with permission from Krassioukov. ${ }^{2}$

studies ${ }^{35-37}$ were all delimited to paraplegics with injuries between T4 and L1, some of whom would be expected to retain partial-to-full supraspinal sympathetic control of the critical splanchnic bed, which may explain the reduced severity of orthostatic hypotension in those studies. It is highly likely that paraplegics with an injury at or above T6, who exhibit no remaining supraspinal sympathetic control of the splanchnic bed, would exhibit marked orthostatic hypotension; however, this postulate remains to be tested. Finally, it is also important to note that none of the studies, which investigated severity of orthostatic hypotension, confirmed autonomic completeness of injury. We have previously shown autonomic completeness of injury to be one of the most important determinants of cardiovascular function. ${ }^{38}$

Further to persistent hypotension, patients with SCI above T6 regularly experience life-threatening episodic bouts of extreme hypertension (up to a systolic blood pressure of $300 \mathrm{~mm} \mathrm{Hg}$ ) that is accompanied by pronounced bradycardia, a disorder known as AD. ${ }^{39}$ During $\mathrm{AD}$, both noxious and non-noxious stimuli below the lesion, such as bowel or bladder distension, could cause exaggerated activation of the spinal circuits caudal to the injury that project to the sympathetic pre-ganglionic neurons. In turn, this usually triggers a sympathetically mediated peripheral vasoconstriction in the gut, muscle and skin vascular beds, causing extreme systemic hypertension. ${ }^{25,40}$ Finally, a parasympathetic-induced bradycardia could be present during episodes of $\mathrm{AD}$ as a baroreflex-mediated response to the hypertension. ${ }^{25}$ Episodes of $\mathrm{AD}$ are commonly accompanied by pounding headaches and upper-body flushing, while below the lesion there is pale and cold skin due to significant vasoconstriction. If left untreated, $\mathrm{AD}$ can cause serious complications, including intracranial hemorrhage, myocardial infarction, retinal detachments, seizures and even death. ${ }^{41-44}$ Although there is still no consensus on the exact pathophysiology explaining $\mathrm{AD}$, it is generally accepted that loss of supraspinal input to the spinal sympathetic circuits, reduced overall sympathetic activity, disruption of spinal reflexes and plastic changes in the spinal cord and peripheral autonomic circuits all contribute to the development of $\mathrm{AD} .^{2}$ In addition to the debilitating consequences of $\mathrm{AD}$ noted above, it is also possible that such repetitive and significant blood pressure elevations could induce a shear injury to the blood vessel endothelium, predisposing these individuals to cardiovascular complications in the future. ${ }^{45}$

\section{BLOOD VESSEL STRUCTURE AND CONTROL}

As blood transcends from the heart to the tissue, it moves from large elastic arteries, through muscular arteries and arterioles into thinwalled capillaries, where nutrient and gas exchange occurs. The arteries and arterioles are composed of three main layers, tunica intima, tunica media and tunica adventitia (Figure 2). The tunica intima consists of a single layer of endothelial cells, which are conjoined to the arterial wall by a narrow layer of connective tissue; the tunica media is formed of bundles of smooth muscle cells intermingled with elastic fibers, and the tunica adventitia is formed of irregularly shaped collagen fibers. Although arteries and arterioles have the same global structure, each type of vessel has a specific structure that reflects the primary function of the vessel. For example, large conduit arteries have a thicker media (more smooth muscle cells), while in the tunica adventitia, there is increased collagen and elastin; these structural adaptations enable conduit vessels to produce the Windkessel effect of maintaining constant pressure despite the pulsatile blood flow. On the other hand, arterioles provide the major site of resistance to blood flow and are thus composed of a just a few layers of smooth muscle in the vessel wall. It is the arterioles that are also responsible for slowing blood flow to ensure adequate time for gas and nutrient exchange within the capillaries; consequently, the arterioles form the primary site for vascular resistance and are, therefore, of primary importance in the regulation of blood pressure.

All arterioles exhibit a state of partial constriction at rest that is termed myogenic tone. The degree of myogenic tone is determined by both intrinsic and extrinsic factors. Intrinsic factors include: 


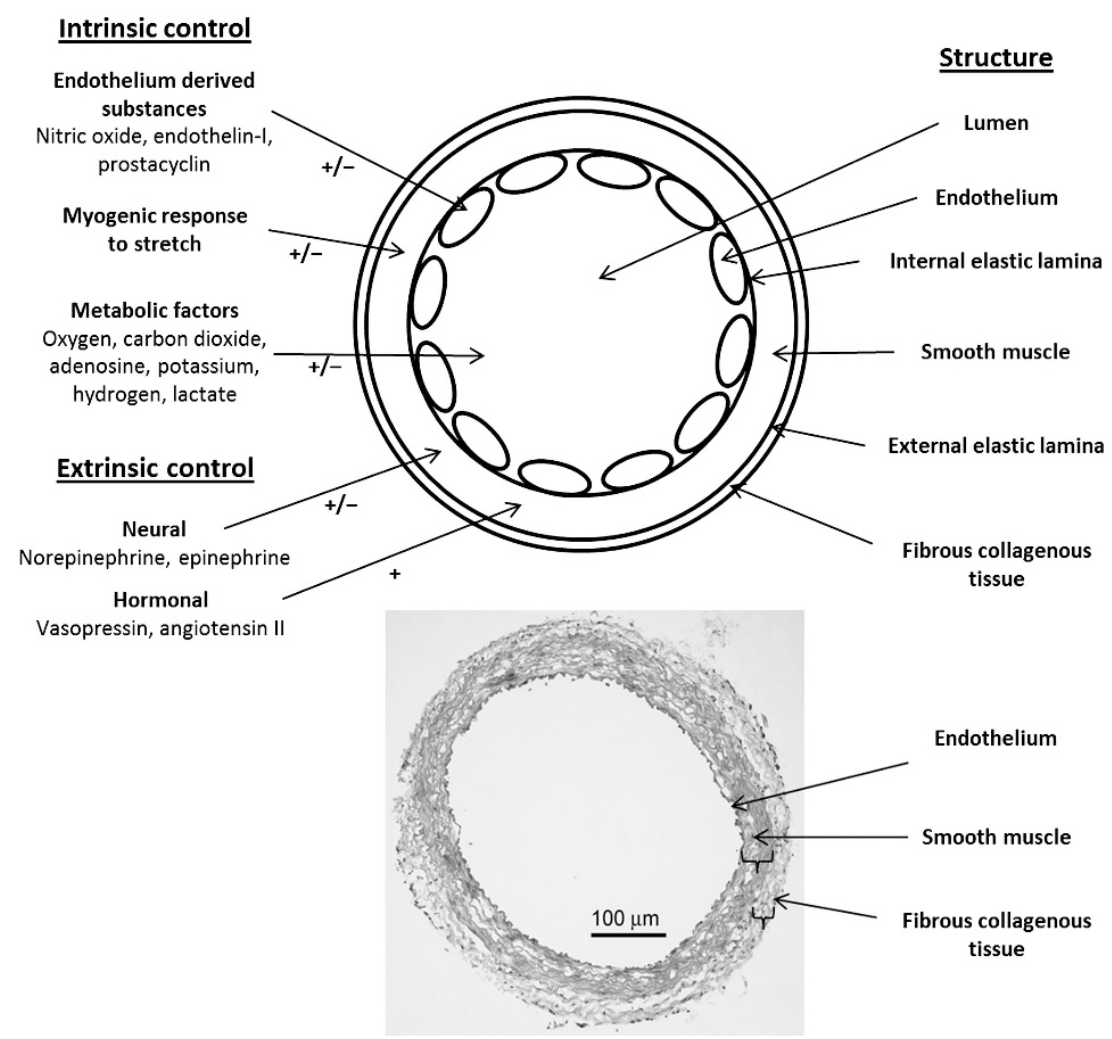

Figure 2 (Top panel) Schematic detailing the control and structure of an arteriole: $(+)$ vasoconstriction; ( - ) vasodilatation. (Bottom panel) Hematoxylinand eosin-stained cryostat section taken from the primary branch of the superior mesenteric artery. Thickness of the smooth muscle and fibrous collagenous tissue is denoted within parantheses.

endothelial factors, local chemical substances and hormones, metabolic by-products or hypoxia, and the myogenic response triggered by changes in intravascular pressure (Figure 2). Although the specific molecules involved in the myogenic response of arterioles is still far from understood, it is generally accepted that the smooth muscle membrane potential depolarizes to increase $\mathrm{Ca}^{2}+$ influx and triggers interaction of actin and myosin through changes in their relative regulatory enzymes. ${ }^{46,47}$ Further to intrinsic factors, there are also extrinsic neural and hormonal factors that affect arteriolar diameter, of which the SNS is the most important in the peripheral circulation. Sympathetic nerve fibers innervate all arteriolar smooth muscles, and $\mathrm{NE}$ released from such nerve endings acts via $\alpha$-adrenoceptors to cause vasoconstriction. Other hormones that are primarily responsible for extrinsically influencing arteriolar diameter are nitric oxide, endothelin, vasopressin and angiotensin. The structure and control of blood vessels is summarized in Figure 2.

\section{CONDUIT ARTERIAL FUNCTION AFTER SCI}

Structural adaptations

It is well known that the vasculature responds to acute and chronic stimuli. Acute alterations are mediated primarily by changes in sympathetic activity to the smooth muscle, whereas chronic changes are mediated primarily by changes in blood flow and pressure, which alters shear stress and consequently the number of smooth muscle cells in vessel walls. ${ }^{48}$ Remodeling of peripheral arteries in paralyzed limbs occurs soon after SCI; within weeks there is a significant reduction in systemic blood volume ${ }^{49}$ and a consequent inward remodeling of the arterial wall, ${ }^{50}$ such that the diameter of the common femoral artery is $30-50 \%$ smalle $^{51-54}$ and resting blood flow in the leg is $30-40 \%$ lower than in $\mathrm{AB}$ individuals. ${ }^{54,55}$ Compared with the inactive lower limbs, the active upper limb vasculature is relatively well preserved. For example, the diameters of the common carotid artery ${ }^{51,53}$ and brachial artery ${ }^{50}$ are similar between SCI and AB. Thus, it appears the structural adaptations below the injury are primarily an adaptation to the reduced metabolic demands of the lower limb vasculature. Indeed, in the only study to account for the reduced metabolic demand by correcting common femoral artery diameter for leg muscle volume, it was reported that femoral artery diameter and peak femoral blood flow after leg occlusion were not different between SCI and $\mathrm{AB}$ participants. ${ }^{56}$ Further to the adaptations that occur in the first 6 weeks after injury, there is evidence to suggest that chronic stiffening of the arterial system also occurs after SCI. ${ }^{57,58}$ This is particularly worrying given that arterial stiffening is a significant independent risk factor for the development of CVD in the $\mathrm{AB}$ population. ${ }^{59}$

\section{Functional adaptations}

Shear stress. Shear stress is described as the frictional force of blood against the endothelium, and is equal to the local blood viscosity multiplied by local wall shear rate (which is calculated by dividing the velocity of blood flow by lumen radius). Shear stress is considered to be a key regulator of endothelial function, which in turn is independently linked to $\mathrm{CVD}^{6}{ }^{60}$ Arteries respond to chronic changes in blood flow by altering their internal diameter such that changes in shear stress are minimized. However, shear stress and shear rate in the common femoral artery in individuals with SCI are 
$50-100 \%$ greater than in $\mathrm{AB}$ individuals. ${ }^{51,53,54}$ The almost doubled shear rate appears to be a consequence of the inactivity rather than loss of supraspinal sympathetic control, as both tetraplegics (decreased sympathetic tone to a nearly all of the vasculature) and low paraplegics (decreased sympathetic tone to approximately half of the vasculature) demonstrate similar increases in shear stress compared with $\mathrm{AB}$ controls. ${ }^{51}$ It should be noted that shear stress is inversely proportional to arterial diameter cubed at constant flow and viscosity. Thus, it has been postulated that inactivity increases shear rate via a reduction in femoral diameter and a consequent increase in velocity. ${ }^{61}$

Endothelial function. The vascular endothelium is a single layer of cells that maintains anticoagulation properties, inhibits smooth muscle proliferation, modulates vascular permeability and enables fine control of the vascular diameter. The most commonly used method to assess endothelial function in humans is flow-mediated dilatation (FMD), which measures the ability of the blood vessels to accommodate increases in flow by altering their internal diameter, and is dependent on nitric oxide (NO) release by endothelial cells. ${ }^{62}$ Several studies document a direct independent relationship between the risk for cardiovascular events and the degree of brachial FMD in non-SCI individuals, ${ }^{63-65}$ whereby the degree of cardiovascular risk is increased as the degree of brachial FMD is reduced.

In individuals with SCI, FMD has been examined in the superficial femoral artery (SFA), ${ }^{62,66,67}$ the posterior tibial artery, ${ }^{68}$ brachial artery $^{67}$ and the radial artery. ${ }^{68}$ In the SFA, individuals with SCI exhibit an increased absolute FMD compared with $\mathrm{AB}$ individuals; ${ }^{69}$ however, this difference is no longer present when the degree of FMD is corrected for area under the shear rate curve, from the time of occluding cuff deflation to that of peak diameter attainment. ${ }^{62}$ Such correction for the eliciting shear stress stimulus on the endothelial cell membrane is considered critical, especially in cases where arteries are compared with different baseline diameters (for example, SCI vs control) ${ }^{61}$ In the only study to investigate brachial artery FMD, it was reported that absolute brachial artery FMD is not different between $\mathrm{SCI}$ and $\mathrm{AB}$ individuals, whereas brachial artery FMD expressed relative to the shear rate stimulus (in this case the change in shear rate ratio from rest to peak hyperemic response) was reduced in SCI compared with $\mathrm{AB} .{ }^{67}$

Enhanced or preserved FMD below the lesion and a reduction in FMD above the lesion appears counterintuitive given the known positive relationship between the degree of physical activity and FMD in $A B .{ }^{70-72}$ Such differences in FMD above and below the lesion may be attributed to the structural adaptations that occur following SCI. Indeed, there is an inverse relationship between vessel size and the relative FMD. ${ }^{73,74}$ Thus a smaller deconditioned SFA may be expected to exhibit enhanced FMD, whereas an enlarged brachial artery may be expected to exhibit a reduced FMD. Unfortunately, the only study directly to test this postulate by examining differences in FMD above and below the lesion in similar-sized arteries reported that SCI individuals exhibit a similar reduction in FMD above and below the injury, suggesting that differences in baseline diameter do not fully explain the differences in FMD. ${ }^{68}$ However, because of technical difficulties with the measurement of hyperemic blood flow velocity in the lower limb, this study was limited by the non-correction of FMD for shear rate in the lower limbs. Thus, future studies are required to confirm whether changes in baseline diameter explain the preserved or enhanced FMD below the lesion in SCI. Alternative explanations for an enhanced FMD below the lesion may be explained by chronic elevations in shear stress and a subsequent heightened sensitivity of
$\mathrm{NO}$ /augmented expression of nitric oxide synthase in vascular smooth muscle, ${ }^{75}$ although this appears unlikely since intra-arterial infusions of sodium nitroprusside (an NO donor) results in a similar degree of SFA vasodilatation in SCI and AB individuals. ${ }^{66}$ Taken together, these findings suggest that FMD is enhanced or at least preserved below the lesion after SCI. Unfortunately, changes in arterial structure and shear stress complicate and hinder our quest to attribute such changes to a particular mechanism. To date, the literature has also assumed that FMD responses should be interpreted in the same way in SCI individuals as it is in $\mathrm{AB}$. Indeed, no study has examined the relationship between the degree of FMD and risk for CVD in the SCI population, and no study has validated the use of FMD as an indicator of endothelial function in deconditioned limbs. Until such studies are carried out, the functional importance of the FMD findings remains to be determined.

\section{RESISTANCE ARTERIES}

\section{Structural adaptations}

There is very little data regarding remodeling of the resistance arteries following SCI, which is surprising given that the resistance vessels are crucial to blood pressure regulation. Furthermore, individuals with SCI experience dramatic alterations in blood pressure control; thus, one may hypothesize that the degree of vascular remodeling may be exacerbated in such resistance vessels. Structural adaptations in resistance vessels are most commonly assessed by measuring the maximal hyperemic responses to limb ischemia. ${ }^{76-78}$ This technique, which has been common place since the late 1950s, is based on the assumption that peak-reactive hyperemia in response to ischemia is limited by maximal cross-sectional area of the resistance vessel. More recently, there is evidence to suggest that that hyperemic blood flow responses in such vessels hold true prognostic value for predicting future cardiovascular events. ${ }^{79,80}$ In the only study to investigate resistance artery remodeling in SCI, individuals with chronic SCI exhibited a $40-60 \%$ reduction in SFA-reactive hyperemia compared with $\mathrm{AB}$ individuals. ${ }^{67}$ This far exceeds values that occur in healthy $\mathrm{AB}$ individuals who undergo acute ${ }^{81}$ or chronic ${ }^{82}$ bed rest. Remodeling of resistance arteries appears to be at least partly attributable to general muscle atrophy, as lower-limb-reactive hyperemia corrected per unit muscle volume is similar between SCI and $\mathrm{AB} .{ }^{56}$

\section{Functional adaptations}

Physiologically, it is reasonable to assume that loss of supraspinal sympathetic control will induce maximal dilatation in the peripheral arteries and a consequent reduction in peripheral vascular resistance. The most accessible peripheral arteries to study in humans are the arteries of extremities. Although a reduction in leg vascular resistance in individuals with SCI has been reported in one study, ${ }^{83}$ the majority of studies report the opposite, that is, leg vascular resistance, measured during supine rest, is increased following SCI. ${ }^{35,84-86}$ The mechanism(s) responsible for the increased leg vascular resistance do not appear to be related to loss of centrally mediated sympathetic tonic control, as graded infusions of phentalomine (competitive antagonist of $\alpha$-adrenoceptors) during $\beta$-adrenoceptor blockade induced a similar degree of upper-leg vasodilation in SCI compared with $\mathrm{AB}$, indicating that $\alpha$-adrenergic tone is relatively well preserved in the legs of individuals with SCI. ${ }^{84}$ Instead, increased vascular resistance may be accounted for by alterations in vasoconstrictor pathways. For example, sympathetic hypoactivity following high thoracic or cervical SCI causes a reduction in circulating levels of epinephrine and $\mathrm{NE},{ }^{87}$ which may be compensated for by 
hypersensitivy to vasoconstrictor substances. Indeed, tetraplegics have an enhanced pressor response to intravenous NE infusions ${ }^{88-90}$ and to phenylephrine (PE), an NE mimetic that is more specific to $\alpha$-adrenoceptors. ${ }^{88}$ Although such hypersensitivity may be explained partly by an impairment of the arterial baroreflex, ${ }^{88}$ it still remains unclear in humans whether the enhanced pressor response actually results from post-synaptic hypersensitivity, as impaired re-uptake of NE may also account for such a response. There is also growing evidence that other vasoconstrictor pathways, such as angiotensin $\mathrm{II}^{88,91}$ and endothelin $\mathrm{I},{ }^{85}$ may also contribute to the increased vascular resistance in the lower limbs of individuals with SCI.

Animal studies investigating hypersensitivity of $\alpha$-adrenoceptors after SCI have reported contrasting results. In second-order mesenteric (resistance) arteries of SCI rats, studies investigating $\alpha$-adrenoceptor hypersensitivity via direct in vitro arterial preparations have reported an enhanced pressor response to PE compared with shaminjured controls. ${ }^{92}$ In the tail artery, $\alpha$-adrenoceptor hypersensitivity appears to be present in the acute (2 weeks), but not chronic (8 weeks) phase post injury. ${ }^{93}$ The mechanism underlying this potential hypersensitivity of the $\alpha$-adrenoceptors appears to be of peripheral rather than central origin, as rats that have undergone sympathetic decentralization exhibit a similar $\alpha$-adrenoceptor hypersensitivity (that is, transient, but not chronic) as SCI rats. ${ }^{94}$ The peripheral mechanism responsible for the enhanced pressor response does not appear to be endothelial dysfunction, as acetylcholine (endothelium-dependent)induced vasorelaxation is normal following T3 SCI in rodents. ${ }^{16}$ Instead, others have suggested that impaired neuronal re-uptake of $\mathrm{NE}$ and $\mathrm{PE},{ }^{92,95}$ and/or increased reactivity of the vascular smooth muscle $e^{93}$ may be responsible for the enhanced pressor response to PE. However, it is also likely that other explanations for such hypersensitivity must exist as PE is metabolized in the liver by phase I and phase II enzyme systems (mainly monoamine oxidase) and is, therefore, not a substrate for neuronal re-uptake.

The functional consequences of any potential adrenoceptor hypersensitivity are also still not clear, and there appears to be disconnects between the animal and human literature. In humans, there is a growing body of evidence that suggests that peripheral adrenoceptor hypersensitivity may be partly responsible for the development of $\mathrm{AD}$ in individuals with $\mathrm{SCI} .{ }^{89}$ For instance, it has been shown that individuals with high SCI exhibit a marked blood pressure response to bladder distension compared with individuals with low SCI or $\mathrm{AB} .{ }^{96}$ The pressor response to bladder distension was not associated with increased plasma NE, renin, aldosterone, vasopressin or arginine, suggesting such a response was due to adrenoceptor hypersensitivity. The same research group also studied the effect of prazosin (a selective $\alpha$-adrenoceptor antagonist) in individuals with high SCI who experienced $\mathrm{AD}$ on a daily basis. ${ }^{97}$ They reported a reduction in the frequency and severity of $\mathrm{AD}$ in those treated with prazosin, further implicating the role of adrenoceptor hyper-responsiveness in the development of $\mathrm{AD}$. However, in animals with high thoracic SCI, it appears that $\alpha$ adrenoceptor hypersensitivity and enhanced severity of $\mathrm{AD}$ are not mutually exclusive. On the contrary, it has been reported that daily induction of a $30 \mathrm{~min}$ bout of $\mathrm{AD}$ via colorectal distension caused $\alpha$ adrenoceptor hypersensitivity, but this was accompanied by a less severe pressor response to a single bout of colorectal distension (that is, reduced severity of $\mathrm{AD}) .{ }^{16}$ Thus, future studies are required to determine whether $\alpha$-adrenoceptor hypersensitivity occurs after SCI and the potential effect of such hypersensitivity on the cardiovascular system.

\section{Microvascular changes after SCI}

Compared with conduit artery function, remarkably little is known about the microcirculation after SCI. Using a local heating protocol to examine NO-mediated vasodilation of the skin, it has been reported that cutaneous vascular conductance (CVC) below the injury is either impaired $^{98,99}$ or preserved. ${ }^{100}$ There is also evidence that CVC is reduced in the arms of paraplegic individuals. ${ }^{99}$ Interestingly, the altered CVC in SCI does not seem to be a consequence of inactivity as an 8-week FES cycling intervention did not alter CVC in either the arms or the legs. ${ }^{99}$ The lack of change in CVC with exercise is probably due to the small active muscle mass involved in FES cycling, which would be expected to impart little change in core body temperature and skin temperature. Furthermore, an increase in core body temperature in SCI is also associated with smaller changes in skin blood flow compared with uninjured individuals. ${ }^{101}$ Hence, it is unlikely that FES cycling provided a sufficient change in skin blood flow to cause any chronic changes in CVC. The lack of exerciseinduced change in the microcirculation is in contrast to conduit arteries, which respond positively to exercise (see 'Deconditioninginduced alterations in blood vessels' below). Thus, it appears that vascular changes with exercise in SCI are not consistent among all vascular beds.

\section{ABNORMAL BLOOD PRESSURE AND STRUCTURAL ALTERATIONS IN THE VASCULATURE}

Data from $A B$ hypertensive patients provide clear insight into changes within the small blood vessels that result from chronic elevations of arterial blood pressure. ${ }^{102-104}$ It is now widely accepted that chronic constriction of the blood vessels, particularly at the level of the resistance vessels, results in locally damaging increases in blood flow velocity and turbulence that can increase shear stress, damage the endothelium and produce maladaptive remodeling of the vasculature. ${ }^{105-107}$ Indeed, Rizzoni et al. ${ }^{108}$ reported that such structural alterations in the small arteries represent the most potent predictor for CVD in the hypertensive population. Less is known about the effects of intermittent or episodic hypertension per se. It is the arterioles that provide the major site of resistance to blood flow in the circulation, and any repeated constriction at this level may cause a sustained hypertension and a chronic fixed pattern of narrowing in these arterioles. ${ }^{109}$ In this regard, rodent studies have revealed that repeated episodes of blood vessel constriction stimulates arteriolar smooth muscle cell proliferation and hypertrophy, as well as connective tissue formation, eventually leading to increased arteriolar wall thickness, ${ }^{110,111}$ which is characteristic of the fixed hypertensive state. ${ }^{104,112}$

In the only study to examine the effect of episodic hypertension per se on vascular endothelial function in SCI, it was reported that 2 weeks of repetitively induced AD in rodents with T3 SCI exacerbates injury-induced hypersensitivity to $\mathrm{PE}$ in superior mesenteric arteries (Figure 3), but does not appear to alter endothelial function. ${ }^{16}$ That study, however, only assessed hypersensitivity following a relatively short time span of induced $\mathrm{AD}$; thus, the long-term effects of such blood pressure oscillations in SCI remain unknown. There are several lines of evidence from other pathological states that suggest chronic blood pressure oscillations damage the vascular endothelium. For example, animal models reveal that experimental alterations in arterial hemodynamics can produce endothelial damage. ${ }^{113}$ Furthermore, numerous studies have demonstrated that preeclampsia, an intermittent hypertensive state that occurs for a short period of time in $4-5 \%$ of human pregnancies, is associated with both early and late vascular dysfunction. ${ }^{114,115}$ Specifically, 
endothelial function estimated by FMD is chronically impaired in preeclampsic vs non-preeclampsic females, ${ }^{116}$ and the vascular smooth muscle of females with preeclampsia exhibits hypersensitivity to vasopressors such as angiotensin. ${ }^{117}$ Such similarities between preeclampsia and SCI suggest that blood pressure oscillations may contribute to vascular dysfunction. However, to date this intriguing hypothesis is yet to be tested in humans with SCI and there is a lack of animal data demonstrating how spontaneously occurring $\mathrm{AD}$, which is known to occur multiple times per day in animal models of SCI, ${ }^{118}$ affects the vasculature.

\section{DECONDITIONING-INDUCED ALTERATIONS IN VASCULATURE}

A likely contributor to the vascular dysfunction exhibited by individuals with SCI is inactivity. A number of studies have investigated the effect of inactivity on arterial dynamics in $\mathrm{AB}$ individuals, and these have been reviewed elsewhere. ${ }^{119,120}$ Briefly, using horizontal bed rest as a model for inactivity, it has been reported that vessel diameter and blood flow are reduced, endothelial function is impaired and shear stress and peripheral resistance are increased. ${ }^{82}$ It has also been shown that the structural alterations resulting from inactivity can be ameliorated with regular physical activity, ${ }^{70}$ and that such changes occur within days or weeks of the onset of exercise. ${ }^{71,72}$
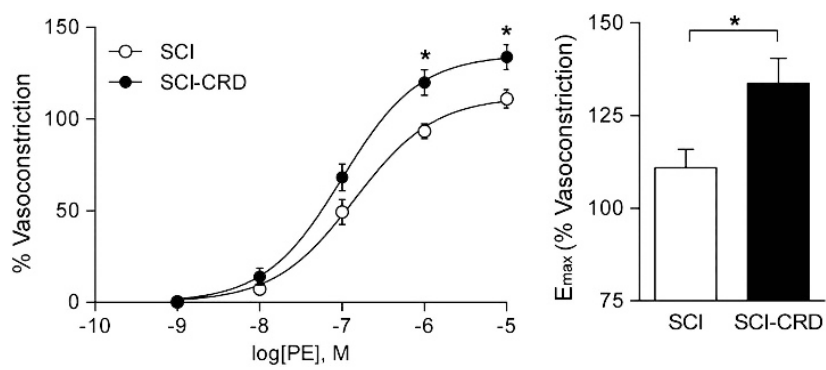

Figure 3 Repetitive colorectal distension (CRD) during recovery from $\mathrm{SCl}$ potentiated PE-induced vasoconstriction. (Left panel) PE concentrationresponse curves for mesenteric arteries from SCl-only controls (SCI, $n=5$ ) and those from animals that underwent repetitive colorectal distension $(\mathrm{SCl}$ CRD, $n=5$ ) revealed that arteries from SCl-CRD animals exhibited larger responses to PE. (Right panel) Maximum vasoconstriction (in response to $\left.10^{-5} \mathrm{M} \mathrm{PE} ; E_{\max }\right)$ was greater in arteries from SCI-CRD animals. Values are mean \pm s.e.m. ${ }^{*} P<0.05$. Figure adapted with permission from Alan et al. ${ }^{16}$
To understand how inactivity affects arterial dynamics in SCI, numerous studies have investigated arterial structure and function in response to a variety of exercise training interventions, of which hybrid exercise and FES cycle exercise have received the most attention. These studies have been reviewed previously ${ }^{121}$ and will not be discussed further; however, a brief summary of these studies is warranted. Hybrid exercise, which incorporates upper body armcrank exercise with lower body FES, improves femoral artery function via increases in basal arterial blood flow, ${ }^{122,123}$ peak blood flow, ${ }^{123}$ diameter, ${ }^{122}$ and FMD. ${ }^{122}$ Similarly, FES cycling alone has been demonstrated to increase femoral artery blood flow, ${ }^{52,86,124}$ improve compliance in small arteries ${ }^{125}$ and femoral arteries, ${ }^{69}$ normalize femoral artery endothelial function, ${ }^{69}$ reduce leg vascular resistance ${ }^{86}$ and improve the femoral hyperemic blood flow response. ${ }^{52}$ Unfortunately, many of those studies are limited by a small number of subjects and the lack of an appropriate control group (that is, lesion-matched SCI control group who do not undertake the exercise intervention). Despite these shortcomings, the dependency of any changes in arterial dynamics on exercise has been demonstrated by Thijjsen et al., ${ }^{122}$ who showed that the improvements in vascular function following FES cycle training returned to baseline values within 1-6 weeks of exercise cessation (Figure 4).

Improved vascular function in response to exercise is consistent with a number of other populations who exhibit an increased CVD risk. ${ }^{61}$ In these populations, it appears likely that the exercise-induced improvement in vascular function is due to an increased shear stress and enhanced NO bioactivity. ${ }^{126}$ To our knowledge, no study has investigated whether similar mechanisms underlie the exerciseinduced improvement in vascular function in people with SCI. Interestingly, data from other populations at risk of CVD has demonstrated that exercise-induced improvements in vascular function may be dose-dependent and represent a balance between oxidative stress and NO bioavailability. For instance, high-intensity exercise, which is associated with increased oxidative stress, may negate the potential increase in NO bioavailability that is observed with moderate-intensity exercise. ${ }^{127}$ Given individuals with SCI exhibit an increased oxidative stress ${ }^{128,129}$ and systemic inflammation, ${ }^{130}$ it is highly likely that any improvements in vascular function in SCI will be heavily dose-dependent. Thus, future studies should attempt to elucidate the mechanistic basis for vascular changes after SCI and the optimum type and dose of exercise required to elicit improvements in vascular function.
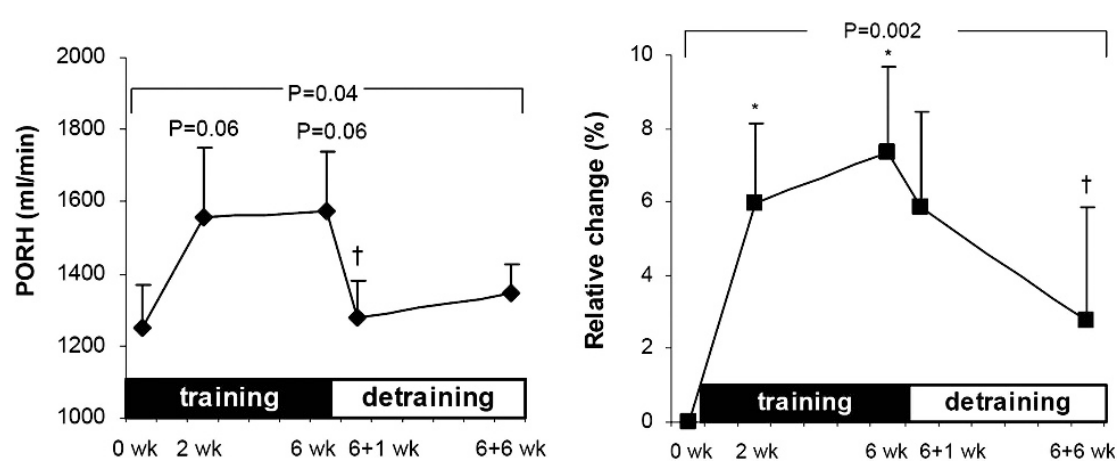

Figure 4 Changes in femoral artery function in response to training and detraining. (Left panel) Peak obstructive-reactive hyperemia (PORH) increased after 2 weeks of training, remained elevated at 6 weeks and was reduced to pre-exercise values within 1 week of exercise cessation. ${ }^{*}$ Significant post hoc compared to week 6. (Right panel) Femoral artery diameter increased after 2 weeks of training, remained elevated at 6 weeks and was reduced to preexercise values within 6 weeks of exercise cessation. *Significant post hoc compared to week 0; 'significant post hoc compared to week 6 . Figure adapted with permission from Thijssen et al. ${ }^{122}$ 
To our knowledge, only two studies have investigated the effect of exercise on cardiovascular function in animals with SCI. Collins et al. ${ }^{131}$ reported that acute ( 1 bout) treadmill exercise reduced the severity of $\mathrm{AD}$ induced via colorectal distension. Although those authors attributed this reduction in $\mathrm{AD}$ severity to an exerciseinduced reduction in $\alpha$-adrenoceptor hypersensitivity, no measures of hypersensitivity were included in their experimental design; hence, the mechanistic basis for the acute reduction in $\mathrm{AD}$ severity could not be determined. In the only study to investigate the long-term effects of exercise training on cardiovascular function, Laird et al. ${ }^{132}$ reported that 6 weeks ( 10 min per day, $5 \times$ a week) of treadmill training exacerbated the severity of $\mathrm{AD}$, enhanced the renal pressor response to $\mathrm{PE}$ and increased calcitonin gene-related peptide immunoreactivity in lamina III/IV of the lumbar spinal cord, the latter of which suggests sprouting of small diameter spinal afferents that may contribute to the heightened $\mathrm{AD}$ severity. Exacerbation of $\mathrm{AD}$ and heightened vascular dysfunction after long-term exercise training in a rodent model of SCI appears to be at odds with the known beneficial effects of exercise on cardiovascular function in humans with SCI (see above). However, as only one study has investigated the vascular responses to long-term exercise training in rodents with SCI, future studies are urgently required to further our understanding of the potential effects of exercise in this population.

\section{CONCLUSIONS}

Individuals with SCI exhibit vascular dysfunction below the lesion that is characterized by a reduction in conduit artery diameter and blood flow, increased shear rate and leg vascular resistance, and adrenoceptor hyper-responsiveness. Although the mechanisms underlying vascular dysfunction following SCI remain to be elucidated, there is emerging evidence that blood pressure oscillations, such as those occurring in the large majority of individuals with SCI, could potentially exacerbate vascular dysfunction. Further to changes in the peripheral conduit and resistance vasculature, there is alarming evidence for central arterial stiffening in individuals with SCI. Such stiffening is likely to contribute to the early onset of CVD, which is currently the number one cause of mortality in the SCI population. Fortunately, it is likely that exercise provides a means by which vascular dysfunction can be ameliorated; however, the mechanistic basis by which exercise improves vascular function remains to be determined. Nevertheless, the evidence in human studies to date suggests that individuals with SCI should be encouraged to undertake regular exercise to reduce the secondary cardiovascular complications associated with SCI.

\section{CONFLICT OF INTEREST}

The authors declare no conflict of interest.

\section{ACKNOWLEDGEMENTS}

Dr C West is supported by an ICORD International Scholarship.

Dr Krassioukov and Dr Laher are recipients of a grant from the Canadian Heart and Stroke Foundation and research in the laboratory of Dr Krassioukov is supported by the Canadian Foundation for Innovation, BC Knowledge Translation Foundation, Canadian Institute for Health Research and a grant from King Saud University.

1 Devivo MJ. Epidemiology of traumatic spinal cord injury: trends and future implications. Spinal Cord 2012; 50: 365-372.

2 Krassioukov A. Autonomic function following cervical spinal cord injury. Respir Physiol Neurobiol 2009; 169: 157-164.
3 Bilello JF, Davis JW, Cunningham MA, Groom TF, Lemaster D, Sue LP. Cervical spinal cord injury and the need for cardiovascular intervention. Arch Surg 2003; 138: 1127-1129.

4 Wu JC, Chen YC, Liu L, Chen TJ, Huang WC, Cheng H et al. Increased risk of stroke after spinal cord injury: a nationwide 4-year follow-up cohort study. Neurology 2012; 78: 1051-1057.

5 Garshick E, Kelley A, Cohen SA, Garrison A, Tun CG, Gagnon D et al. A prospective assessment of mortality in chronic spinal cord injury. Spinal Cord 2005; 43: 408-416.

6 D'Agostino RB, Vasan RS, Pencina MJ, Wolf PA, Cobain M, Massaro JM et al. General cardiovascular risk profile for use in primary care. Circulation 2008; 117: 743-753.

7 Krum H, Howes LG, Brown DJ, Ungar G, Moore P, McNeil JJ et al. Risk factors for cardiovascular disease in chronic spinal cord injury patients. Paraplegia 1992; 30: 381-388.

8 West CR, Mills P, Krassioukov AV. Influence of the neurological level of spinal cord injury on cardiovascular outcomes in humans: a meta-analysis. Spinal Cord 2012; 50: 484-492.

9 Cragg JJ, Stone JA, Krassioukov AV. Management of cardiovascular disease risk factors in individuals with chronic spinal cord injury: an evidence-based review. J Neurotrauma 2012; 29: 1999-2012.

10 Mora S, Cook N, Buring JE, Ridker PM, Lee IM. Physical activity and reduced risk of cardiovascular events: potential mediating mechanisms. Circulation 2007; 116: 2110-2118.

11 Green DJ, Maiorana AJ, Cable NT. Point: exercise training does induce vascular adaptations beyond the active muscle beds. J App/ Physiol 2008; 105: 1002-1004; discussion 1007.

12 Joyner MJ, Green DJ. Exercise protects the cardiovascular system: effects beyond traditional risk factors. J Physiol 2009; 587(Part 23): 5551-5558.

13 Krassioukov AV, Fehlings MG. Effect of graded spinal cord compression on cardiovascular neurons in the rostro-ventro-lateral medulla. Neuroscience 1999; 88: 959-973.

14 Krenz NR, Meakin SO, Krassioukov AV, Weaver LC. Neutralizing intraspinal nerve growth factor blocks autonomic dysreflexia caused by spinal cord injury. J Neurosci 1999; 19: 7405-7414.

15 Krassioukov AV, Bygrave MA, Puckett WR, Bunge RP, Rogers KA. Human sympathetic preganglionic neurons and motoneurons retrogradely labelled with Dil. J Auton Nerv Syst 1998; 70: 123-128.

16 Alan N, Ramer LM, Inskip JA, Golbidi S, Ramer MS, Laher I et al. Recurrent autonomic dysreflexia exacerbates vascular dysfunction after spinal cord injury. Spine J 2011; 10: 1108-1117.

17 Suzuki N, Hardebo JE. The cerebrovascular parasympathetic innervation. Cerebrovasc Brain Metab Rev 1993; 5: 33-46.

18 Krassioukov AV, Weaver LC. Anatomy of the autonomic nervous system. In: Teasell R and Baskerville VB (eds) Physical Medicine and Rehabilitation: State of the Art Reviews. Hanley \& Belfus, Medical Publishers: Philadelphia, pp 1-14, 1996.

19 Alexander MS, Biering-Sorensen F, Bodner D, Brackett NL, Cardenas D, Charlifue S et al. International standards to document remaining autonomic function after spinal cord injury. Spinal Cord 2009; 47: 36-43.

20 Piepmeier JM, Lehmann KB, Lane JG. Cardiovascular instability following acute cervical spinal cord trauma. Cent Nerv Syst Trauma 1985; 2: 153-160.

21 Hadley M. Blood pressure management after acute spinal cord injury. Neurosurgery 2002; 50(Suppl): S58-S62

22 Mathias CJ, Frankel HL. Clinical manifestations of malfunctioning sympathetic mechanisms in tetraplegia. J Auton Nerv Sys 1983; 7: 303-312.

23 Krassioukov A, Eng JJ, Warburton DE, Teasell R. A systematic review of the management of orthostatic hypotension after spinal cord injury. Arch Phys Med Rehabil 2009; 90: 876-885.

24 Lehmann KG, Lane JG, Piepmeier JM, Batsford WP. Cardiovascular abnormalities accompanying acute spinal cord injury in humans: incidence, time course and severity. J Am Coll Cardiol 1987; 10: 46-52.

25 Teasell RW, Arnold JMO, Krassioukov A, Delaney GA. Cardiovascular consequences of loss of supraspinal control of the sympathetic nervous system after spinal cord injury. Arch Phys Med Rehabil 2000; 81: 506-516.

26 Grigorean VT, Sandu AM, Popescu M, lacobini MA, Stoian R, Neascu C et al. Cardiac dysfunctions following spinal cord injury. J Med Life 2009; 2: 133-145.

27 Bush VE, Wight VL, Brown CM, Hainsworth R. Vascular responses to orthostatic stress in patients with postural tachycardia syndrome (POTS), in patients with low orthostatic tolerance, and in asymptomatic controls. Clin Auton Res 2000; 10: 279-284.

28 Brown CM, Hainsworth R. Forearm vascular responses during orthostatic stress in control subjects and patients with posturally related syncope. Clin Auton Res 2000; 10: $57-61$

29 Wallin BG, Stjernberg L. Sympathetic activity in man after spinal cord injury. Brain 1984; 107: 183-198.

30 Munakata M, Kameyama J, Nunokawa T, Ito N, Yoshinaga K. Altered Mayer wave and baroreflex profiles in high spinal cord injury. Am J Hypertens 2001; 14: 141-148.

31 Faghri PD, Yount J. Electrically induced and voluntary activation of physiologic muscle pump: a comparison between spinal cord-injured and able-bodied individuals. Clin Rehabil 2002; 16: 878-885.

32 Vaziri ND. Nitric oxide in microgravity-induced orthostatic intolerance: relevance to spinal cord injury. J Spinal Cord Med 2003; 26: 5-11.

33 Frisbie $\mathrm{JH}$. Postural hypotension, hyponatremia, and salt and water intake: case reports. J Spinal Cord Med 2004; 27: 133-137. 
34 Sidorov EV, Townson AF, Dvorak MF, Kwon BK, Steeves J, Krassioukov A. Orthostatic hypotension in the first month following acute spinal cord injury. Spinal Cord 2008; 46: 65-69.

35 Groothuis JT, Boot CR, Houtman S, van Langen H, Hopman MT. Leg vascular resistance increases during head-up tilt in paraplegics. Eur J Appl Physiol 2005; 94 408-414.

36 Raymond J, Davis GM, Bryant G, Clarke J. Cardiovascular responses to an orthostatic challenge and electrical-stimulation-induced leg muscle contractions in individuals with paraplegia. Eur J Appl Physiol Occup Physiol 1999; 80: 205-212.

37 Grimm DR, De Meersman RE, Almenoff PL, Spungen AM, Bauman WA. Sympathovagal balance of the heart in subjects with spinal cord injury. Am J Physiol 1997; 272(Part 2): H835-H842.

38 West CR, Romer LM, Krassioukov A. Autonomic function and exercise performance in elite athletes with cervical spinal cord injury. Med Sci Sports Exerc 2012, (in press).

39 Krassioukov A, Warburton DE, Teasell R, Eng JJ. A systematic review of the management of autonomic dysreflexia after spinal cord injury. Arch Phys Med Rehabil 2009; 90: 682-695.

40 Krassioukov A, Claydon VE. The clinical problems in cardiovascular control following spinal cord injury: an overview. Prog Brain Res 2006; 152: 223-229.

41 Ho CP, Krassioukov AV. Autonomic dysreflexia and myocardial ischemia. Spinal Cord48: 714-715

42 Yarkony GM, Katz RT, Wu YC. Seizures secondary to autonomic dysreflexia. Arch Phys Med Rehabil 1986; 67: 834-835.

43 Pine ZM, Miller SD, Alonso JA. Atrial fibrillation associated with autonomic dysreflexia. Am J Phys Med Rehabil 1991; 70: 271-273.

44 Eltorai I, Kim R, Vulpe M, Kasravi H, Ho W. Fatal cerebral hemorrhage due to autonomic dysreflexia in a tetraplegic patient: case report and review. Paraplegia 1992; 30: 355-360.

45 Steins SA, Johnson MC, Lyman PJ. Cardiac rehabilitation in patients with spinal cord injuries. Phys Med Rehabil Clin N Am 1995; 6: 263-296.

46 Somlyo AP, Somlyo AV. Signal transduction and regulation in smooth muscle. Nature 1994; 372: 231-236.

47 Hill MA, Meininger GA, Davis MJ, Laher I. Therapeutic potential of pharmacologically targeting arteriolar myogenic tone. Trends Pharmacol Sci 2009; 30: 363-374.

48 Silver AE, Vita JA. Shear-stress-mediated arterial remodeling in atherosclerosis: too much of a good thing? Circulation 2006; 113: 2787-2789.

49 Houtman S, Oeseburg B, Hopman MT. Blood volume and hemoglobin after spinal cord injury. Am J Phys Med Rehabil 2000; 79: 260-265.

50 de Groot PC, Bleeker MW, van Kuppevelt DH, van der Woude LH, Hopman MT. Rapid and extensive arterial adaptations after spinal cord injury. Arch Phys Med Rehabil 2006; 87: 688-696

51 Boot CR, Groothuis JT, Van Langen H, Hopman MT. Shear stress levels in paralyzed legs of spinal cord-injured individuals with and without nerve degeneration. J App/ Physiol 2002; 92: 2335-2340.

52 Nash MS, Montalvo BM, Applegate B. Lower extremity blood flow and responses to occlusion ischemia differ in exercise-trained and sedentary tetraplegic persons. Arch Phys Med Rehabil 1996; 77: 1260-1265.

53 Schmidt-Trucksass A, Schmid A, Brunner C, Scherer N, Zach G, Keul J et al. Arterial properties of the carotid and femoral artery in endurance-trained and paraplegic subjects. J Appl Physiol 2000; 89: 1956-1963.

54 De Groot PC, Van Kuppevelt DH, Pons C, Snoek G, Van Der Woude LH, Hopman MT. Time course of arterial vascular adaptations to inactivity and paralyses in humans. Med Sci Sports Exerc 2003; 35: 1977-1985.

55 Taylor PN, Ewins DJ, Fox B, Grundy D, Swain ID. Limb blood flow, cardiac output and quadriceps muscle bulk following spinal cord injury and the effect of training for the Odstock functional electrical stimulation standing system. Paraplegia 1993; 31: 303-310.

56 Olive JL, Dudley GA, McCully KK. Vascular remodeling after spinal cord injury. Med Sci Sports Exerc 2003; 35: 901-907.

57 Miyatani M, Masani K, Oh PI, Miyachi M, Popovic MR, Craven BC. Pulse wave velocity for assessment of arterial stiffness among people with spinal cord injury: a pilot study. J Spinal Cord Med 2009; 32: 72-78.

58 Wecht JM, Weir JP, DeMeersman RE, Spungen AM, Bauman WA. Arterial stiffness in persons with paraplegia. J Spinal Cord Med 2004; 27: 255-259.

59 Mattace-Raso FU, van der Cammen TJ, Hofman A, van Popele NM, Bos ML, Schalekamp MA et al. Arterial stiffness and risk of coronary heart disease and stroke: the Rotterdam Study. Circulation 2006; 113: 657-663.

60 Davies PF. Hemodynamic shear stress and the endothelium in cardiovascular pathophysiology. Nat Clin Pract Cardiovasc Med 2009; 6: 16-26.

61 Thijssen DH, Maiorana AJ, O'Driscoll G, Cable NT, Hopman MT, Green DJ. Impact of inactivity and exercise on the vasculature in humans. Eur J App/ Physiol 2010; 108 845-875.

62 Kooijman M, Thijssen DH, de Groot PC, Bleeker MW, van Kuppevelt HJ, Green DJ et al. Flow-mediated dilatation in the superficial femoral artery is nitric oxide mediated in humans. J Physiol 2008; 586: 1137-1145.

63 Gonzalez MA, Selwyn AP. Endothelial function, inflammation, and prognosis in cardiovascular disease. Am J Med 2003; 115(Suppl 8A): 99S-106S

64 Muiesan ML, Salvetti M, Paini A, Monteduro C, Galbassini G, Poisa P et al. Prognostic role of flow-mediated dilatation of the brachial artery in hypertensive patients. J Hypertens 2008; 26: 1612-1618

65 Kuvin JT, Patel AR, Sliney KA, Pandian NG, Rand WM, Udelson JE et al. Peripheral vascular endothelial function testing as a noninvasive indicator of coronary artery disease. J Am Coll Cardiol 2001; 38: 1843-1849.
66 Thijssen DH, Kooijman M, de Groot PC, Bleeker MW, Smits P, Green DJ et al. Endothelium-dependent and -independent vasodilation of the superficial femoral artery in spinal cord-injured subjects. J App/ Physiol 2008; 104: 1387-1393.

67 de Groot PC, Poelkens F, Kooijman M, Hopman MT. Preserved flow-mediated dilation in the inactive legs of spinal cord-injured individuals. Am J Physiol Heart Circ Physiol 2004; 287: H374-H380.

68 Stoner L, Sabatier M, VanhHiel L, Groves D, Ripley D, Palardy G et al. Upper vs lower extremity arterial function after spinal cord injury. J Spinal Cord Med 2006; 29 138-146.

69 de Groot P, Crozier J, Rakobowchuk M, Hopman M, MacDonald M. Electrical stimulation alters FMD and arterial compliance in extremely inactive legs. Med Sci Sports Exerc 2005; 37: 1356-1364.

70 Clarkson P, Montgomery HE, Mullen MJ, Donald AE, Powe AJ, Bull T et al. Exercise training enhances endothelial function in young men. J Am Coll Cardiol 1999; 33: 1379-1385.

71 McAllister RM, Laughlin $\mathrm{MH}$. Short-term exercise training alters responses of porcine femoral and brachial arteries. J App/ Physiol 1997; 82: 1438-1444.

72 Allen JD, Geaghan JP, Greenway F, Welsch MA. Time course of improved flowmediated dilation after short-term exercise training. Med Sci Sports Exerc 2003; 35: 847-853.

73 Celermajer DS, Sorensen KE, Gooch VM, Spiegelhalter DJ, Miller OI, Sullivan ID et al. Non-invasive detection of endothelial dysfunction in children and adults at risk of atherosclerosis. Lancet 1992; 340: 1111-1115.

74 Schroeder S, Enderle MD, Baumbach A, Ossen R, Herdeg C, Kuettner A et al. Influence of vessel size, age and body mass index on the flow-mediated dilatation (FMD\%) of the brachial artery. Int J Cardiol 2000; 76: 219-225.

75 Uematsu M, Ohara Y, Navas JP, Nishida K, Murphy TJ, Alexander RW et al. Regulation of endothelial cell nitric oxide synthase mRNA expression by shear stress. Am J Physiol 1995; 269(Part 1): C1371-C1378.

76 Folkow B. The fourth Volhard lecture: cardiovascular structural adaptation; its role in the initiation and maintenance of primary hypertension. Clin Sci Mol Med Suppl 1978; 4: 3s-22s.

77 Patterson GC, Whelan RF. Reactive hyperaemia in the human forearm. Clin Sci (Lond) 1955; 14: 197-211.

78 Silber $\mathrm{DH}$, Sinoway $\mathrm{LI}$. Reversible impairment of forearm vasodilation after forearm casting. J Appl Physiol 1990; 68: 1945-1949.

79 Anderson TJ, Charbonneau F, Title LM, Buithieu J, Rose MS, Conradson $\mathrm{H}$ et al. Microvascular function predicts cardiovascular events in primary prevention: longterm results from the Firefighters and Their Endothelium (FATE) study. Circulation 2011; 123: 163-169.

80 Lind L, Berglund L, Larsson A, Sundstrom J. Endothelial function in resistance and conduit arteries and 5-year risk of cardiovascular disease. Circulation 2011; 123 1545-1551.

81 Hamburg NM, McMackin CJ, Huang AL, Shenouda SM, Widlansky ME, Schulz E et al. Physical inactivity rapidly induces insulin resistance and microvascular dysfunction in healthy volunteers. Arterioscler Thromb Vasc Biol 2007; 27: 26502656.

82 Bleeker MW, De Groot PC, Rongen GA, Rittweger J, Felsenberg D, Smits P et al. Vascular adaptation to deconditioning and the effect of an exercise countermeasure: results of the Berlin bed rest study. J Appl Physiol 2005; 99: 1293-1300.

83 Casiglia E, Pizziol A, Piacentini F, Biasin R, Onesto C, Tikhonoff V et al. 24-Hour leg and forearm haemodynamics in transected spinal cord subjects. Cardiovasc Res 1999; 41: 312-316.

84 Kooijman M, Rongen GA, Smits P, Hopman MT. Preserved alpha-adrenergic tone in the leg vascular bed of spinal cord-injured individuals. Circulation 2003; 108: 2361-2367. 85 Thijssen DH, Ellenkamp R, Kooijman M, Pickkers P, Rongen GA, Hopman MT et al. A causal role for endothelin-1 in the vascular adaptation to skeleta muscle deconditioning in spinal cord injury. Arterioscler Thromb Vasc Biol 2007; 27: 325-331.

86 Hopman MT, Groothuis JT, Flendrie M, Gerrits KH, Houtman S. Increased vascular resistance in paralyzed legs after spinal cord injury is reversible by training. J Appl Physiol 2002; 93: 1966-1972.

87 Schmid A, Huonker M, Barturen JM, Stahl F, Schmidt-Trucksass A, Konig D et al. Catecholamines, heart rate, and oxygen uptake during exercise in persons with spinal cord injury. J Appl Physiol 1998; 85: 635-641.

88 Krum H, Louis WJ, Brown DJ, Howes LG. Pressor dose responses and baroreflex sensitivity in quadriplegic spinal cord injury patients. J Hypertens 1992; 10 245-250.

89 Arnold JM, Feng QP, Delaney GA, Teasell RW. Autonomic dysreflexia in tetraplegic patients: evidence for alpha-adrenoceptor hyper-responsiveness. Clin Auton Res 1995; 5: 267-270.

90 Mathias CJ, Frankel HL, Christensen NJ, Spalding JM. Enhanced pressor response to noradrenaline in patients with cervical spinal cord transection. Brain 1976; 99: 757-770.

91 Groothuis JT, Thijssen DH, Rongen GA, Deinum J, Danser AH, Geurts AC et al. Angiotensin II contributes to the increased baseline leg vascular resistance in spinal cord-injured individuals. J Hypertens 2010; 28: 2094-2101.

92 Brock JA, Yeoh M, McLachlan EM. Enhanced neurally evoked responses and inhibition of norepinephrine reuptake in rat mesenteric arteries after spinal transection. Am J Physiol Heart Circ Physiol 2006; 290: H398-H405.

93 Yeoh M, McLachlan EM, Brock JA. Tail arteries from chronically spinalized rats have potentiated responses to nerve stimulation in vitro. J Physiol 2004; 556(Part 2): 545-555. 
94 Yeoh M, McLachlan EM, Brock JA. Chronic decentralization potentiates neurovascular transmission in the isolated rat tail artery, mimicking the effects of spinal transection. J Physiol 2004: 561(Part 2): 583-596.

95 Laird AS, Finch AM, Waite PM, Carrive P. Peripheral changes above and below injury level lead to prolonged vascular responses following high spinal cord injury. Am J Physiol Heart Circ Physiol 2008; 294: H785-H792.

96 Krum H, Louis WJ, Brown DJ, Clarke SJ, Fleming JA, Howes LG. Cardiovascular and vasoactive hormone responses to bladder distension in spinal and normal man. Paraplegia 1992; 30: 348-354.

97 Krum H, Louis WJ, Brown DJ, Howes LG. A study of the alpha-1 adrenoceptor blocker prazosin in the prophylactic management of autonomic dysreflexia in high spinal cord injury patients. Clin Auton Res 1992; 2: 83-88.

98 Nicotra A, Asahina M, Mathias CJ. Skin vasodilator response to local heating in human chronic spinal cord injury. Eur J Neurol 2004; 11: 835-837.

99 Van Duijnhoven NT, Janssen TW, Green DJ, Minson CT, Hopman MT, Thijssen DH. Effect of functional electrostimulation on impaired skin vasodilator responses to local heating in spinal cord injury. J Appl Physiol 2009; 106: 1065-1071.

100 Nicotra A, Asahina M, Young TM, Mathias CJ. Heat-provoked skin vasodilatation in innervated and denervated trunk dermatomes in human spinal cord injury. Spinal Cord 2006; 44: 222-226.

101 Freund PR, Brengelmann GL, Rowell LB, Halar E. Attenuated skin blood flow response to hyperthermia in paraplegic men. J App/ Physiol 1984; 56: 1104-1109.

102 Schiffrin EL. Small artery remodeling in hypertension: can it be corrected? Am J Med Sci 2001; 322: 7-11

103 Rizzoni D, Porteri E, Platto C, Rizzardi N, De Ciuceis C, Boari GE et al. Morning rise of blood pressure and subcutaneous small resistance artery structure. J Hypertens 2007; 25: 1698-1703.

104 Rizzoni D, De Ciuceis C, Porteri E, Paiardi S, Boari GE, Mortini P et al. Altered structure of small cerebral arteries in patients with essential hypertension. J Hypertens 2009; 27: 838-845.

105 Schiffrin EL. Remodeling of resistance arteries in essential hypertension and effects of antihypertensive treatment. Am J Hypertens 2004; 17(Part 1): 1192-1200.

106 Triggle CR, Howarth A, Cheng ZJ, Ding H. Twenty-five years since the discovery of endothelium-derived relaxing factor (EDRF): does a dysfunctional endothelium contribute to the development of type 2 diabetes? Can J Physiol Pharmacol 2005; 83: 681-700.

107 Philpott AC, Lonn E, Title LM, Verma S, Buithieu J, Charbonneau F et al. Comparison of new measures of vascular function to flow mediated dilatation as a measure of cardiovascular risk factors. Am J Cardiol 2009; 103: 1610-1615.

108 Rizzoni D, Porteri E, Boari GE, De Ciuceis C, Sleiman I, Muiesan ML et al. Prognostic significance of small-artery structure in hypertension. Circulation 2003; 108 2230-2235

109 Folkow B, Hallback M, Lundgren Y, Sivertsson R, Weiss L. Importance of adaptive changes in vascular design for establishment of primary hypertension, studied in man and in spontaneously hypertensive rats. Circ Res 1973; 32(Suppl 1): 2-16.

110 Kochova P, Tonar Z, Matejka VM, Sviglerova J, Stengl M, Kuncova J. Morphology and mechanical properties of the subrenal aorta in normotensive and hypertensive rats. Biomed Pap Med Fac Univ Palacky Olomouc Czech Repub 2008; 152: 239-245.

111 Ledingham JM, Ashton N. Remodelling of mesenteric arteries in genetically hypertensive rats cross-fostered from birth to normotensive Wistar rats. Clin Exp Pharmacol Physiol 2005; 32: 859-864.

112 Mulvany MJ. Small artery remodelling in hypertension. Basic Clin Pharmacol Toxicol 2012; 110: 49-55
113 Fry DL. Acute vascular endothelial changes associated with increased blood velocity gradients. Circ Res 1968; 22: 165-197.

114 VanWijk MJ, Kublickiene K, Boer K, VanBavel E. Vascular function in preeclampsia. Cardiovasc Res 2000; 47: 38-48.

115 Sankaralingam S, Arenas IA, Lalu MM, Davidge ST. Preeclampsia: current understanding of the molecular basis of vascular dysfunction. Expert Rev Mol Med 2006; 8: $1-20$

116 Agatisa PK, Ness RB, Roberts JM, Costantino JP, Kuller LH, McLaughlin MK. Impairment of endothelial function in women with a history of preeclampsia: an indicator of cardiovascular risk. Am J Physiol Heart Circ Physiol 2004; 286: H1389-H1393.

117 Gant NF, Daley GL, Chand S, Whalley PJ, MacDonald PC. A study of angiotensin II pressor response throughout primigravid pregnancy. J Clin Invest 1973; 52: 2682-2689.

118 Rabchevsky AG, Patel SP, Lyttle TS, Eldahan KC, O'Dell CR, Zhang Y et al. Effects of gabapentin on muscle spasticity and both induced as well as spontaneous autonomic dysreflexia after complete spinal cord injury. Front Physiol 2012; 3: 329.

119 Thijssen DH, Green DJ, Hopman MT. Blood vessel remodeling and physical inactivity in humans. J Appl Physiol 2011; 111: 1836-1845.

120 de Groot PC, Bleeker MW, Hopman MT. Magnitude and time course of arterial vascular adaptations to inactivity in humans. Exerc Sport Sci Rev 2006; 34: 65-71.

121 Phillips AA, Cote AT, Warburton DE. A systematic review of exercise as a therapeutic intervention to improve arterial function in persons living with spinal cord injury. Spinal Cord 2011; 49: 702-714.

122 Thijssen DH, Ellenkamp R, Smits P, Hopman MT. Rapid vascular adaptations to training and detraining in persons with spinal cord injury. Arch Phys Med Rehabil 2006; 87: 474-481.

123 Thijssen DH, Heesterbeek P, van Kuppevelt DJ, Duysens J, Hopman MT. Local vascular adaptations after hybrid training in spinal cord-injured subjects. Med Sci Sports Exerc 2005; 37: 1112-1118.

124 Gerrits HL, de Haan A, Sargeant AJ, van Langen H, Hopman MT. Peripheral vascular changes after electrically stimulated cycle training in people with spinal cord injury. Arch Phys Med Rehabil 2001; 82: 832-839.

125 Zbogar D, Eng JJ, Krassioukov AV, Scott JM, Esch BT, Warburton DE. The effects of functional electrical stimulation leg cycle ergometry training on arterial compliance in individuals with spinal cord injury. Spinal Cord 2008; 46: 722-726.

126 Hambrecht R, Adams V, Erbs S, Linke A, Krankel N, Shu Y et al. Regular physical activity improves endothelial function in patients with coronary artery disease by increasing phosphorylation of endothelial nitric oxide synthase. Circulation 2003; 107: 3152-3158.

127 Goto C, Higashi Y, Kimura M, Noma K, Hara K, Nakagawa K et al. Effect of different intensities of exercise on endothelium-dependent vasodilation in humans: role of endothelium-dependent nitric oxide and oxidative stress. Circulation 2003; 108 : 530-535.

128 Jia Z, Zhu H, Li J, Wang X, Misra H, Li Y. Oxidative stress in spinal cord injury and antioxidant-based intervention. Spinal Cord 2011; 50: 264-274.

129 Hall ED. Antioxidant therapies for acute spinal cord injury. Neurotherapeutics 2011; 8: $152-167$.

130 Garshick E, Stolzmann KL, Gagnon DR, Morse LR, Brown R. Systemic inflammation and reduced pulmonary function in chronic spinal cord injury. Phys Med Rehab 2011; 3: 433-439.

131 Collins HL, Dicarlo SE. Acute exercise reduces the response to colon distension in T5 spinal rats. Am J Physiol-Heart Circ Physiol 2002; 282: H1566-H1570.

132 Laird AS, Carrive P, Waite PM. Effect of treadmill training on autonomic dysreflexia in spinal cord-injured rats. Neurorehab Neural Repair 2009; 23: 910-920. 